\title{
Sex differences in phonological processes: Speeded matching and word reading
}

\author{
RAYMOND L. MAJERES \\ Western Illinois University, Macomb, Illinois
}

\begin{abstract}
Sex differences in phonological processing were investigated in four experiments. Two experiments required college students to decide whether two five-letter strings matched. Same-case (AA) pairs of letter strings could be matched using physical features, whereas mixed-case (Aa) pairs of letter strings required the mediation of a speech-based code (letter name) for the comparison. Women were significantly faster than men when the comparisons required the speech-based codes. In another experiment, college students read lists of words and lists of pseudohomophones to determine whether there was a sex difference in the computation of phonology for unfamiliar words (assembled phonology). In a final experiment, students read lists of words with phonologically inconsistent spelling patterns to determine whether there was a sex difference in accessing pronunciations of familiar words (addressed phonology). Women were more proficient than men under both of these conditions. Results were interpreted in terms of a female advantage in both prelexical and lexical processing, an advantage that may stem from a sex difference in the quality of the phonological representations.
\end{abstract}

Phonological processing refers to the use of abstract phonological representations for processing oral and written language. According to Chomsky \& Halle (1968), phonological transformations of a language connect the phonetic surface structures to underlying lexical and abstract phonological representations. These abstract representations are not "speech sounds" nor are they vocalized or subvocalized speech, though they mediate such activities (Frost, 1998), and they share much in common with the speech-based information that is stored and rehearsed in Baddeley's (1992) phonological loop. These speech-based representations of speech as well as the related articulatory representations are both implicated in cognitive differences between men and women (McGuinness, 1981).

Recent evidence of a sex difference in hemispheric specialization may shed some light on the nature of the sex difference in the use of speech-based codes (Pugh et al., 1997; Shaywitz et al., 1995). During phonological processing, judging whether pronounceable nonwords rhymed, women on the average showed greater righthemisphere activation (inferior frontal gyrus and extrastriate region) than did men. According to Pugh et al., these regions are believed to be associated with the processing of letters in a serial and small-grained manner (phonemes and phoneme clusters). Both men and women showed

I am grateful to Larry Beatty, Connie Butts, Dennis Abry, Melissa Paoni, and Dan Perunko for their assistance in data collection and to the students who participated in these studies. In addition, I thank William Syrcle, Gene Smith, reviewer Donald Shankweiler, and an anonymous reviewer for their helpful comments on an earlier draft of this article. Correspondence should be addressed to R. L. Majeres, Department of Psychology, Western Illinois University, Macomb, IL 61455 (e-mail: ray_majeres@ccmail.wiu.edu). comparable levels of activation in analogous regions of the left hemisphere, regions involved in the processing of larger units (e.g., syllable rimes and morphemes) and in a parallel mode. Hence, women were more likely than men to activate those regions of both hemispheres that are most strongly associated with phonological processing (Pugh et al., 1997).

Women have been found to be consistently faster and more accurate than men in symbol matching (Fairweather, 1976; Guilford, 1967; Maccoby \& Jacklin, 1974, Table 2.10 - see "perceptual" and "clerical speed" entries; Majeres, 1977, 1988, 1990; Schneidler \& Paterson, 1942). Speeded symbol matching has been used as a reference test for an important dimension of human cognitive ability called perceptual speed (Carroll, 1993) and is a very good predictor of early reading problems (Kerns \& Decker, 1985). From four standardizations of the Differential Aptitude Test conducted between 1947 and 1980, Feingold (1988) reported significant sex differences in all four data sets, with females performing better than males on the clerical speed and accuracy measure. There was evidence of a decline in the size of the difference over the period, but the sex difference was still substantial and there is reason to believe that the reported decrement may have been due to shifts in the types of students in the samples. According to Halperin (1989), (1) there was a shift in the dropout rate from more girls to more boys in the 1970 s, thus lowering the mean for high school girls and raising it for boys, and (2) when low-ability students are not included in standardized testing in high school, the more numerous low-verbal-ability boys are excluded, which raises the mean for the boys. This would result in a net decrease in sex differences over the time period.

Prior to Guilford's (1967) survey, the female advantage observed on speeded matching tests had been explained in 
terms of a sex difference in rapid recognition and shifts in attention (see, e.g., Garai \& Scheinfeld, 1968). Guilford criticized this interpretation and proposed that the sex difference on perceptual speed tests (1) is due to a sex difference in comparison and decision processes rather than perceptual encoding, recognition, or shifts of attention, and (2) is restricted to comparisons that involve symbols (letters and digits) but not figural stimuli. Later research has supported both of these claims (Majeres, 1977, 1983, 1990).

For example, on a recognition task in which two strings of digits were shown sequentially so that the second string had to be compared with a memory representation, a sex difference was not found. However, on an evaluation task in which the two strings of digits were presented together, a significant sex difference was found (Majeres, 1988). This was interpreted as evidence that the sex difference on speeded symbol matching was not the result of a sex difference in recognition (matching a previously seen string), but was due to a sex difference related to symbol comparison and decision processes, as suggested by Guilford (1967).

The importance of the symbolic or verbal content was demonstrated in an early study in which geometric shapes (square, circle, and triangle) were matched by tapping either the name of the shape or shapes on response cards (Majeres,1977, Experiment 2). In all cases, only when names appeared on the response cards were women faster than men. Although content of the response card was related to the sex variable, there was evidence that men and women did not differ in terms of recognition processes. That is, the type of list (words, shapes, or lists with both words and shapes) was unrelated to the sex variable, a result that would be unexpected if women had an advantage over men in word recognition.

The sex difference in speeded matching also has been shown to be related to the encoding demands of the task. For example, when strings of digits were presented in close proximity, one above the other, a reliable sex difference was not found. Yet, when the digit strings were presented side by side and with a small displacement, a significant sex difference was found (Majeres, 1990, Experiment 2). This finding was interpreted in terms of a shift in the type of code used in the comparison. For example, in a vertical arrangement with one string directly above the other, comparisons could be made readily using physical appearance. However, in a horizontally displaced arrangement, judgments on the basis of physical appearance may have been more difficult, resulting in the use of digit names to make the matches. If comparisons can be made readily (vertical arrangement of digits) at a figural level, participants will employ this strategy. But, if the comparison process is delayed (the horizontal arrangement), encoding will go beyond the figural level and the comparisons will be made using name codes. It is under the latter condition that a significant sex difference was found.

In two of the present studies, Experiments 1 and 2, this formulation was explicitly tested by using strings of let- ters for which the comparison could be made on the basis of physical identity (all uppercase letters) and strings of letters for which matching required using the names of letters to make the comparisons (mixed-case letters, requiring Posner's (1978) Aa-type matches). It was predicted that the sex difference would be larger under the mixed-case than under the same-case condition.

Experiments 3 and 4 were investigations of the possibility that the sex difference in speech-based processing believed to be involved in the speeded comparison of symbols might also be found on a task that did not involve comparison and decision processes, but that did require substantial phonological processing. The tasks selected required the reading of lists of pronounceable nonwords or the reading of words under conditions that might lead to phonological conflict.

\section{EXPERIMENT 1}

The purpose of this experiment was to determine whether the distinction between physical versus name matching and the implied coding differences would be sex related. Because name codes are speech-based codes and the involvement of such codes may underlie the sex difference found on speeded matching of symbols, it was predicted that a sex difference would be found when matching was mediated by letter names, but not when matching involved the direct comparison for physical identity.

\section{Method}

Participants. Student volunteers ( 29 male and 26 female students with an average age of 20.5 and 20.9 years, respectively) from introductory psychology classes at a midwestern state university participated for partial course credit. Data from 8 students $(5$ males and 3 females) who failed to follow instructions or had many extremely long response times (more than $2.5 S D$ ) were not used. All students reported normal or corrected-to-normal vision and were native speakers of English.

Materials and Procedures. Fifteen letters of the alphabet were selected, excluding the five vowels and the letters $\mathrm{C}, \mathrm{S}, \mathrm{V}, \mathrm{W}$, and $Z$. Vowels were excluded to avoid familiar multiletter patterns, and the other letters were excluded to avoid certain visual confusions. From the 15 selected letters, three random five-letter sets were formed (BKGNR, DHLTQ, and FMJYP). Of the 120 possible letter orders per set, 30 strings were selected from each set for a total of 90 five-letter strings. These strings were presented in pairs with one string directly below the other. The letters were uppercase in 12 point Chicago font. There were 90 same pairs, where the two strings were identical, and 90 different pairs. The different pairs were created by substituting one letter from outside the set into the lower string. This substitution occurred approximately the same number of times in each of the letter positions. Because the letters were all uppercase, this set of letter-string pairs was called the same-case condition. A mixed-case condition was created using the same letter sets. The only difference was that the lower string of each pair appeared in lowercase. For these pairs, matching had to be based on the letter name because the strings lacked physical identity. There also were 90 pairs of this condition for a total of 180 experimental trials.

Stimuli were presented using an Apple SE computer and monitor with a viewing distance of approximately 25 in. Each pair of letter strings was preceded by a $1-\sec$ fixation point. A response to the pair terminated the display, and the fixation point for the next trial 
was presented. Participants used the index finger on their preferred hand to press one of two adjacent keyboard keys indicating a "yes" (match) or "no" (no match). They were instructed to respond as rapidly as possible without making errors. Response times were recorded from the onset of the pair to the response. The type of pair on any given trial was random. That is, participants did not know ahead of time whether they were to make a "physical" or a "name" match.

\section{Results and Discussion}

The mean response latencies and standard deviations for the matching judgments for men and women are presented in Table 1 . A $2 \times 2 \times 2$ anaiysis of variance (ANOVA) with sex, type of string pair (same- and mixedcase conditions), and judgment (same and different) as variables resulted in a significant main effect for the sex variable $[F(1,45)=5.72, p<.05]$. Women were significantly faster than men on same- and mixed-case matches, and this was true for both same and different judgments. There was a significant main effect for the type of string, with mixed-case pairs requiring more time than samecase pairs $[F(1,45)=301.09, p<.001]$. There was also a significant judgment $\times$ type of string pair interaction $[F(1,45)=149.91, p<.001]$, with the difference between the two types of strings being larger for same than for different judgments.

Although the sex $\times$ type of string pair $\times$ judgment interaction was not significant $[F(1,45)=3.97, p<.06]$, it was in the predicted direction. The sex difference was significant for the mixed-case condition $[t(45)=2.66$, $p<.02]$ and was nearly $50 \%$ greater for this condition (name-mediated matching) than the sex difference for the same-case condition,which was also significant $[t(45)=2.05, p<.05]$. For the different judgments, the interaction effect also was not significant, while the main effect was significant $[F(1,45)=4.68, p<.05]$.

A sex $\times$ judgment $\times$ type of string pair ANOVA of error data indicated a significant judgment effect $[F(1,45)=$ $65.82, p<.001]$, with the error rates for same and different judgments of $2 \%$ and $7 \%$, respectively. There was also a significant sex $\times$ judgment $\times$ type of string pair interaction $[F(1,45)=7.03, p<.05]$. Independent sample $t$ tests of sex differences with Bonferroni adjusted alpha levels indicated one significant contrast $(p<.01)$. Men made more errors than women when making same judgments for the mixed-case pairs (men, $M=1.83, S D=$

Table 1

Mean Response Latencies and Standard Deviations (in Milliseconds) for the Matching of Same-Case (AA) or Mixed-Case (Aa) Letter Strings

\begin{tabular}{|c|c|c|c|c|c|}
\hline \multirow[b]{3}{*}{ Type of Match } & \multirow[b]{3}{*}{ Judgment } & \multicolumn{4}{|c|}{ Sex } \\
\hline & & \multicolumn{2}{|c|}{ Men } & \multicolumn{2}{|c|}{ Women } \\
\hline & & $M$ & $S D$ & $M$ & $S D$ \\
\hline \multirow[t]{2}{*}{ Same case } & Same & 1,768 & 526 & 1,492 & 385 \\
\hline & Different & 1,674 & 374 & 1,439 & 374 \\
\hline \multirow[t]{2}{*}{ Mixed case } & Same & 2,560 & 625 & 2,148 & 413 \\
\hline & Different & 2,013 & 443 & 1,768 & 355 \\
\hline
\end{tabular}

1.79 ; women, $M=.74, S D=1.01$ ). Women tended to be a bit faster and they made fewer errors in making the namemediated matches. However, a marginal interaction and a significant difference in errors in the predicted direction are weak support for the hypothesis that the female advantage in speeded matching stems from an advantage in speech-based codes and their processing.

Contrary to prediction, there were sex differences in matching letter strings across conditions. Whether the string required name-mediated matching (mixed-case condition) or could be based on physical features (samecase condition) had little effect on the size of the sex difference. One possible reason for this outcome may have been the presentation conditions. Since participants did not know the type of match ahead of time, they may have been using name-mediated matching throughout rather than switching the basis for their matching.

\section{EXPERIMENT 2}

The purpose of this experiment was to determine whether the results of Experiment 1 were due to the way the letter strings were presented. In Experiment 2, pairs of letter strings were presented in blocks of like trials and participants knew ahead of time the type of matching required. Also, a block of matching trials that did not use any alphanumeric characters was added. A sex difference would be expected only for the mixed-case letter strings because they require name-mediated matching. A sex difference would not be expected for the same-case letter strings nor for the nonalphanumeric characters because these matches could be made on the basis of physical features alone.

\section{Method}

Participants. Student volunteers ( 33 male and 34 female students with average ages of 21.1 and 21.0 years, respectively) from introductory psychology classes at a midwestern state university served as participants for course credit. Data from 3 participants ( 1 male and 2 females) with more than 15 errors or very long response times (greater than $2.5 S D$ ) were not used. Analyses were based on data from 64 participants, half men and half women. All students reported normal or corrected-to-normal vision and were native speakers of English.

Materials and Procedures. The letter-string pairs in Experiment 2 were the same as in Experiment 1, a third set of stimuli that did not involve letters or digits was also added. This set of stimuli was created from 15 nonalphanumeric keyboard characters: $\{$,$\} ,$ $[],,,^{*}, \&, \%, \#, !, ?,<,>,+$, and $\$$. The 90 pairs were formed by replacing each of the 15 letters with a keyboard character. Half of the pairs were the same and half were different. There were 90 pairs of each of these three conditions (same-case, mixed case, and nonletter pairs of strings) for a total of 270 trials.

In this experiment, the trials were blocked in terms of the type of match required - uppercase, mixed-case, and nonletter trial blocksunlike Experiment 1, in which the order of presentation of the type of string pair was random. The three blocks of trials were given to participants in three counterbalanced orders using a Latin square procedure. The same number of men and women were assigned to each order. Also, there was a slight change in presentation conditions 
in Experiment 2. After the 1-sec fixation point, there was a 500msec blank screen prior to the presentation of the next pair.

\section{Results and Discussion}

There were no sex-related differences in error rates, nor any significant differences in error rates between the three types of symbols, although there tended to be slightly higher rates for the same- and mixed-case letter conditions ( $7.8 \%$ and $8.1 \%$, respectively) than for the nonletter condition $(6.4 \%)$. Mean response latencies for men and women for the three types of string pairs are presented in Table 2 . A sex $\times$ judgment (same or different) $\times$ type of string pair (uppercase, mixed-case, and nonletters) ANOVA yielded a significant main effect for type of judgment, with same judgments taking more time than different judgments $[F(1,62)=65.76, p<.001]$. Also, there was a significant main effect of type of string pair $[F(2,124)=166.95, p<.001]$ as well as a significant judgment $\times$ type of string pair interaction $[F(2,124)=$ $17.38, p<.001]$. Mixed-case letter matching was slower (relative to same-case-letter and nonletter conditions) on the "yes" trials than on the "no" trials, using Bonferroni $t \mathrm{~s}$. The mixed-case matching time was over $600 \mathrm{msec}$ slower than the matching times for the same-case letters and the nonletter characters. Hence, the name-mediated matching (mixed-case matching) required more time than did matching based on physical features (same-case and nonletter matching).

There was a significant main effect of sex $[F(1,62)=$ $7.97, p<.01]$, with women generally being faster than men. However, the sex $\times$ type of string pair interaction was also significant $[F(2,124)=7.96, p<.001]$. Independent sample $t$ tests with Bonferroni adjusted alpha levels indicated that women were significantly faster than men on the mixed-case strings and this was the case for both same and different judgments $(p s<.01)$. On the same-case strings and on the nonalphanumeric string pairs, there were no significant sex differences for either same or different judgments. The prediction was that those matches that were verbally mediated would yield significant sex differences whereas the nonmediated conditions would not. For both the same and different judgments, the results supported this prediction.

The results confirm the hypothesis that when speeded matching is mediated by names, women are faster than

Table 2

Mean Response Latencies and Standard Deviations (in Milliseconds) for the Matching of Two Types of Letter Strings and a Nonletter Control String

\begin{tabular}{llccccc}
\hline & & \multicolumn{3}{c}{ Sex } \\
\cline { 3 - 4 } \cline { 5 - 6 } Type of Match & Judgment & $M$ & $S D$ & & $M$ & $S D$ \\
\cline { 3 - 7 } \cline { 5 - 6 } Same case & Same & 1,625 & 597 & & 1,388 & 439 \\
& Different & 1,502 & 440 & 1,275 & 320 \\
\multirow{2}{*}{ Mixed case } & Same & 2,492 & 573 & 2,031 & 422 \\
& Different & 2,103 & 454 & 1,709 & 292 \\
Nonletter & Same & 1,669 & 526 & 1,508 & 479 \\
& Different & 1,325 & 300 & 1,270 & 235 \\
\hline
\end{tabular}

men. Hence, the sex difference in favor of females in speeded matching is most likely due to the greater facility of women over men in the access and use of speechbased mediators in matching.

\section{EXPERIMENT 3}

Pugh et al. (1997) reported finding a sex difference in cerebral activation when participants were engaged in phonological processing. The right hemispheric region involved is believed to be specialized for the serial processing of small-grained phonological units. According to Frost (1998), reading words initially involves a very fast computation or assembly of an impoverished phonological representation (prelexical representation) that accesses or activates a rich, abstract phonological representation and other lexical information. The reading of pseudowords places strong demands on the computation of the initial phonological representation.

The purpose of this experiment was to investigate sex differences in the speed of reading lists of pseudowords, a task that requires substantially more phonological computation or assembly than the reading of familiar words. Females were expected to read these lists faster than males because of an advantage in the use of speech-based information (Experiment 2), a proficiency that may be apparent in prelexical phonological assembly processes.

\section{Method}

Participants. Student volunteers ( 24 male and 28 female students with average ages of 20.1 and 20.7 years, respectively) from introductory psychology classes at a midwestern state university participated for partial course credit. All students reported normal or corrected-to-normal vision and were native speakers of English.

Material and Procedures. In this experiment, participants read lists of items as rapidly as possible. The lists were taken from Lukatela and Turvey (1993). Four types of lists were used: high- and lowfrequency words, and high- and low-frequency pseudohomophones. Pseudohomophones sound like words, but they are not words. For example, hoap, howse, urly, and roed sound like familiar words, but the spelling is quite different. Since these nonwords are unfamiliar, the pronunciation must be assembled. There were 20 items in each list for a total of 80 items ( 40 words and 40 pseudohomophones).

The lists were presented using an Apple SE computer and monitor. The order of reading the four types of lists was varied so that each list occurred twice in each of the four possible positions. Each of the types of list was read eight times. Participants were instructed to read the list before them as rapidly and as accurately as possible and to press an end-of-list key when finished. After an initial practice list, participants pressed a key and immediately began to read the lists. Time from list onset to the end-of-list keypress served as the dependent variable. When ready for the next list, participants pressed the key and continued. The experimenter sat off to the side, monitoring reading and providing assistance when needed.

\section{Results and Discussion}

Reading times were analyzed with a $2 \times 2 \times 2 \times 2$ (sex $\times$ word frequency $\times$ word type $\times$ trial block) mixed ANOVA. Mean reading times for the first and last four trials were analyzed as trial blocks. It was found that women had faster reading times than men $[F(1,54)=8.99, p<$ $.01]$, that high-frequency words were read faster than low- 
frequency words $[F(1,54)=5.55, p<.05]$, and that reading times decreased with practice $[F(1,54)=82.38, p<$ $.001]$. Also, words were read faster than pseudohomophones $[F(1,54)=159.46, p<.001]$, and the reading of words showed less improvement with practice than the reading of pseudohomophones, which yielded a word type $\times$ trial block interaction $[F(1,54)=74.89, p<.001]$. There was a significant word list $\times$ frequency interaction $[F(1,54)=89.58, p<.001]$, with high-frequency words being read faster than low-frequency words, but the lowfrequency pseudohomophones were read faster than the high-frequency pseudohomophones. Pseudohomophones that sound like very familiar words activate a highly accessible meaning that is incongruent with the orthography, thus producing some delay in processing. The effect is weaker when the pseudohomophones sound like low-frequency words. This effect, which seems to involve semantic interference, was not related to the sex variable.

The finding that high-frequency words were read faster than low-frequency words is consistent with the general observation that frequency effects are an important determinant of speed of word recognition. The failure to find a relationship between the sex variable and word frequency suggests that the sex difference found on word reading is not due to a sex difference in word recognition, but may stem from sex differences later in processing. Because these word list and frequency effects were unrelated to the sex of the participants [word list $\times \operatorname{sex}, F(1,54)=$ 2.87 , n.s.; frequency $\times$ sex, $F(1,54)=.05$, n.s.], the reading times from the word and pseudohomophone lists were collapsed across the frequency variable and the eight reading times were grouped into four trial blocks of two trials each. The mean reading times and standard deviations are given in Table 3 .

A $2 \times 2 \times 4$ (sex $\times$ type of list $\times$ trial block) mixed ANOVA yielded significant main effects of type of word $[F(1,54)=150.45, p<.001]$, trials $[F(3,162)=63.74$, $p<.001]$, and their interaction $[F(3,162)=50.26, p<$ $.001]$. Words were read faster than pseudohomophones, and the practice effect was greater for the pseudohomo-

Table 3

Mean Reading Times and Standard Deviations (in Seconds) for Word and Pseudohomophone Lists

\begin{tabular}{|c|c|c|c|c|}
\hline \multirow{3}{*}{$\begin{array}{c}\text { Trial } \\
\text { Block }\end{array}$} & \multicolumn{4}{|c|}{ Sex } \\
\hline & \multicolumn{2}{|c|}{ Men } & \multicolumn{2}{|c|}{ Women } \\
\hline & $M$ & $S D$ & $M$ & $S D$ \\
\hline \multicolumn{5}{|c|}{ Words } \\
\hline 1 & 10.00 & 1.66 & 9.00 & 1.23 \\
\hline 2 & 9.84 & 1.83 & 8.42 & 1.06 \\
\hline 3 & 9.57 & 1.82 & 8.45 & .97 \\
\hline 4 & 9.58 & 1.93 & 8.41 & .97 \\
\hline \multicolumn{5}{|c|}{ Pseudohomophones } \\
\hline 1 & 14.48 & 4.14 & 12.46 & 2.18 \\
\hline 2 & 13.10 & 3.50 & 10.64 & 2.03 \\
\hline 3 & 12.42 & 3.22 & 10.47 & 1.87 \\
\hline 4 & 11.19 & 2.77 & 10.05 & 1.57 \\
\hline
\end{tabular}

Note-There were 20 items per list. phones than for the words. The main effect of the sex variable was significant $[F(1,54)=9.27, p<.01]$, with women having faster reading times than men. The sex $x$ type of list interaction was not significant $[F(1,54)=2.62$, $p=.11]$, but the sex $\times$ type of list $\times$ trial block interaction was significant $[F(1,54)=5.30, p<.05]$. To clarify this interaction, separate analyses were done for the word and pseudohomophone reading data.

The analysis of word reading times indicated that the main effect of sex was significant $[F(1,54)=10.35, p<$ $.005]$, with women having faster reading times than men (means of 8.57 and $9.75 \mathrm{sec}$, respectively). The main effect of trial block was significant $[F(3,162)=9.96, p<$ $.001]$, and although word reading times improved with practice, the improvement was small. Adjacent trial blocks were not significantly different (Bonferroni $t$ s). The effect of practice was the same for men as for women.

The analysis of pseudohomophone reading times indicated a significant main effect of $\operatorname{sex}[F(1,54)=198.17$, $p<.01$ ], with women faster than men (means of 10.00 and $12.80 \mathrm{sec}$, respectively), and a significant effect of trial block $[F(3,162)=79.19, p<.001]$. Unlike the word reading data, sex $\times$ trial block yielded a significant interaction $[F(3,162)=3.81, p<.05]$. Women were faster than men on Trial Blocks 1, 2, and 3, but not on Trial Block 4 (Bonferroni $t$ s). This interaction indicated that although both men and women experienced difficulty reading pseudohomophones, men experienced more difficulty than women on Trial Blocks 1, 2, and 3.

When reading words, both men and women showed only modest improvement across trial blocks. In contrast, when reading pseudohomophones, the sex difference was twice as large and men and women showed large decreases in reading times from the first to the last trial block. However, the size of the sex difference decreased, so that by the fourth block of trials, the size of the sex difference was similar to that found for word reading.

The results provide some support for the hypothesis of a sex difference in phonological assembly processes. Women were faster than men when reading pseudohomophones, a task that placed high demands on the phonological assembly process. However, this advantage disappeared by the fourth trial block. The nonsignificant sex difference for the fourth trial block suggests that after repeatedly reading the nonwords, there may have been a decrease in the necessity for extensive computational or assembly processes, resulting in the lack of a sex difference after practice.

\section{EXPERIMENT 4}

The purpose of this experiment was to determine whether the reading of familiar words, for which the role of phonological computation or assembly is minimal, would still result in a reliable sex difference. That is, computation is minimal in the sense that abstract phonological representations can be readily activated when the words are familiar (Frost, 1998). 
This experiment involved the rapid reading of lists of familiar words for which the pronunciation was potentially confusing due to the priming of an incompatible pronunciation by the prior word - for example, mint occurring just prior to pint. This conflict would involve the activation of incompatible phonological representations, thus slowing reading time during the resolution process. Since the processes are not prelexical, a sex difference under these conditions might not be observed. Yet, using such lists, Baron (1979) reported that boys experienced more confusion than girls. This result was replicated, again with children, by Treiman (1984).

A main effect of sex for word reading, as in Experiment 3 , would be expected because of recognized differences in verbal fluency and speech production (Halperin, 1992). Finding a significant sex $\times$ condition (conflict vs. no conflict) interaction, with women reading much faster than men on the phonological conflict lists, would suggest that the sex difference in speech-based processing extends beyond prelexical processing and includes lexical processing as well.

\section{Method}

Participants. Student volunteers (26 male and 29 female students with average ages of 19.4 and 20.7 years, respectively) from introductory psychology classes at a midwestern state university participated for partial course credit. Data from 3 students $(2$ males and 1 female) were not used because of a failure to follow instructions. All participants reported normal or corrected-to-normal vision and were native speakers of English.

Materials and Procedures. Two types of word lists from Baron (1979, Experiment 2) were used. In one type, designed to create phonological coding confusion, the students had to read words composed of orthographically similar rimes but different phonology. For example, the first word might be maid and the second word might be said. These words have a similar spelling component, the rime -aid, but a different pronunciation. The first word, maid, serves to prime the more frequent phonetic and articulatory codes. The second word, said, contains the common spelling component but a different pronunciation, which leads to a slowing of reading time. There were two such lists of 18 words (nine pairs) involving this type of phonological conflict. Control lists consisted of pairs of words for which the rimes and the pronunciations were both different. For example, the words made and said involve different rimes and have different pronunciations, whereas when made replaces maid in the control list, the same utterance is still made. There were two such control lists of 18 words. Baron had students read the two conflict lists first and then the two control lists. This was then repeated five times. The same procedure was used in this experiment, except that the lists were read six times.

The lists were presented as in Experiment 3. When participants were ready, a keypress resulted in the presentation of a list and activated a timer. Students read the lists aloud with clear articulation as fast as possible and pressed an end-of-list response key when they finished. The experimenter sat to the side to monitor and ensure compliance with instructions.

\section{Results and Discussion}

The mean reading times on the two alternate forms of each list condition (the two conflict forms and two control forms) were averaged. The mean reading times and stan- dard deviations for the men and women on conflict and noconflict conditions across the six trials are given in Table 4.

A $2 \times 2 \times 6$ ANOVA with sex of participant as a between-subjects variable and type of list (conflict vs. no-conflict lists) and trials as within-subjects variables yielded significant main effects of type of list $[F(1,50)=$ $41.17, p<.001]$ and of trial $[F(5,250)=63.33, p<.001]$. Students read the no-conflict lists faster than the conflict lists, and reading times improved with practice. The main effect of the sex variable was not significant $[F(1,50)=$ $2.39, p>.10$ ], but there was a significant type of list $X$ sex interaction $[F(1,50)=6.25, p<.05]$. The significant type of list $\times$ sex interaction means that men's reading times $(M=.77 \mathrm{sec})$ were significantly slower for the conflict lists than were the women's $(M=.27 \mathrm{sec})$; that is, men experienced more phonological confusion than women, and this was the case across trial blocks. This sex difference decreased with practice, but remained reliable. Separate analyses for men and women indicated that they both experienced greater delays in reading the conflict lists than in reading the no-conflict lists [men, $F(1,23)=$ $21.44, p<.001$; women, $F(1,27)=21.55, p<.001]$, and both showed significant improvement with practice [men, $F(5,115)=20.86, p<.001$; women, $F(5,135)=53.70$, $p<.001]$.

The significant sex $\times$ type of list interaction indicated that the sex difference in phonological processing probably extends beyond the prelexical processes. The sex difference in reading the phonological conflict lists indicates a sex difference in lexical processing. That is, the reading times of women were less affected by the activation of alternative lexical representations. This suggests that the sex difference in phonological processing may not be restricted to the prelexical processes involved in the reading of pseudohomophones (Experiment 3 ).

Table 4

Mean Reading Times and Standard Deviations (in Seconds) on Phonological-Conflict and No-Conflict Word Lists

\begin{tabular}{ccccc}
\hline & \multicolumn{3}{c}{ Sex } \\
\cline { 2 - 5 } Trial & $M$ & $S D$ & $M$ & $S D$ \\
\cline { 2 - 5 } & \multicolumn{5}{c}{ Men } & Conflict & \\
\hline & 9.89 & 2.13 & 9.11 & 1.98 \\
2 & 9.08 & 1.83 & 8.32 & 1.82 \\
3 & 8.84 & 2.57 & 7.87 & 1.81 \\
4 & 8.04 & 1.73 & 7.61 & 1.59 \\
5 & 8.03 & 2.17 & 7.61 & 1.68 \\
6 & 7.78 & 1.92 & 7.40 & 1.60 \\
& & & & \\
1 & 9.11 & 1.98 & 8.70 & 1.40 \\
2 & 8.32 & 1.82 & 7.89 & 1.28 \\
3 & 7.87 & 1.81 & 7.52 & 1.17 \\
4 & 7.61 & 1.59 & 7.25 & 1.08 \\
5 & 7.61 & 1.68 & 7.06 & 1.16 \\
6 & 7.40 & 1.60 & 6.99 & 1.17 \\
\hline
\end{tabular}

Note-There were 18 words per list. 


\section{GENERAL DISCUSSION}

The present results provide support for the hypothesis that the sex difference in the matching of symbols is the result of a sex difference in speech-based processes. On the speeded matching of letters, similar to the type of test frequently used as a marker test for the perceptual speed factor (Carroll, 1993), the sex difference in speed of matching depended on the involvement of speech-based codes. For example, when the matching was name mediated (mixed-case string pairs), women were significantly faster than men. When the letters and nonletter characters could be matched on the basis of physical characteristics, sex differences were not found. This result is consistent with other studies in which the sex difference in speeded matching was found to depend on verbal or symbolic content (Guilford, 1967; Majeres, 1977). The present results are more explicit in that they clearly demonstrate that the sex difference is directly related to the need to use letter names when making the comparisons.

Since adult readers are very familiar with letters, letters would require very minimal prelexical processing, suggesting that the role of prelexical processing in symbol matching is quite limited. The sex difference in symbol matching very likely involves the role of lexical processes in the comparison and decision process. This interpretation is consistent with previous work indicating that the female advantage in symbol matching is strongly associated with comparison and decision processes (Guilford, 1967; Majeres, 1983, 1988, 1990). It is possible that the source of the sex difference in lexical processing is actually the result of a sex difference in the phonological representation.

Pugh et al. (1997) suggested that women were more likely to evidence right-hemisphere activation during phonological processing, and the region of activation is believed to be specialized for the serial processing of small-grained phonological units. This right-hemisphere specialization may have a direct effect on the quality of the abstract phonological representation. The "smallgrained" processing may result in a "sharper" or a more fully specified phonological representation, and these representations may facilitate a variety of processes like the matching of mixed-case letter strings or the reading of pronounceable nonwords.

Experiments 3 and 4 provided further evidence for sex differences in speech-based processing by examining the role of prelexical and lexical phonological processes in reading words and nonwords. In Experiment 3, women read pseudohomophones and words faster than men, but the difference was significantly larger for the pseudohomophones. In reading pseudohomophones, the role of prelexical phonological assembly would be strong, since the pronunciation of a nonword has to be computed or assembled. Hence, the source of the sex difference in phonological processing would seem to be in prelexical processing. This result is consistent with the suspicion that women may be specialized for the serial processing of small-grained phonological units. This specialization in women could explain the female advantage in prelexical processing.

However, this advantage was negligible after about six trials since both men and women were doing as well with pseudohomophones as they were with familiar words by that point. The repeated reading of the nonwords most likely resulted in the rapid formation of the prelexical phonological representation for each nonword, which would reduce the involvement of the assembly process. This reduction in the role of the sex-related assembly process would explain the lack of a sex difference after practice.

In Experiment 3, there were significant word frequency effects within the experiment, although none of them was related to the sex variable. Since word frequency is usually an important contributor to recognition time, this finding suggests that the sex difference in reading time is not the result of a sex difference in recognition processes (how quickly the word was seen). This means that the sex difference in the speed of reading pseudohomophones in this experiment probably was not due to a sex difference in the speed of perceiving the letters in the string, but involves a sex difference in those processes involved in pronouncing the pseudohomophones.

In addition to the sex difference related to prelexical processing in Experiment 3, women were significantly faster readers than men on both nonwords and words. Although not significant, the same trend was apparent in the data from Experiment 4. McGuinness (1981) suggested that women may have a greater degree of integration of the perceptual systems involved in phonetic recognition and the corresponding production systems. Reading aloud requires fully specified phonological representations. So it may be that the quality of these representations in women may, in turn, explain their proficiency in speech production.

Experiment 4 also provided evidence for a sex difference in lexical processing. In this experiment, men were slower at reading words with irregular pronunciations. To make the pronunciation problem more demanding, each of these words was preceded in the list by a regularly pronounced word (e.g., mint and then pint). The reading of familiar words on lists with phonological conflict can be viewed as a matter of trying to access pronunciations from among well-learned patterns. From this point of view, the reading of an irregularly pronounced word involved the suppression of the phonological representation related to the dominant pronunciation, and the selection of the phonological representation related to the less common pronunciation. These are obviously not prelexical processes, yet a significant sex difference was found. Women were more proficient in resolving the conflict between the conflicting phonological representations, and this proficiency persisted across trials. This result seems to reflect a stable, sex-related processing difference involving abstract phonological representations.

Sex differences in right hemispheric involvement during phonological processing (Pugh et al., 1997; Shaywitz 
et al., 1995), along with the proposal that these areas may be specialized for the serial processing of small phonological entities (Pugh et al., 1997), may account for the sex differences in prelexical and lexical processing found in the present studies. These results are consistent with a right-hemisphere specialization in women that results in a more fully specified representation. This phonological representation may facilitate those cognitive processes that utilize these representations, such as the comparison processes in symbol matching, the reading of words that produce a degree of phonological conflict; it probably affects speech production as well.

Recent developments in the understanding of reading disabilities have given a prominent role to phonological processes rather than perceptual difficulties. There is strong evidence that many of these reading problems are related to deficiencies in phonological processing (see, e.g., Rack, Snowling, \& Olson, 1992; Stanovich \& Siegel, 1994). Also, symbol-matching tests have been found to be particularly sensitive predictors of the most common forms of reading disability (Kerns \& Decker, 1985). The reason for this is becoming more apparent. Speeded symbol-matching tests probably share the same phonological processes that are important in learning to read. It is quite likely that many of the early reading and readingrelated problems observed more frequently in boys than in girls (see Halperin, 1992) have as an important causal component a sex difference in phonological processing.

The current impression is that there are few if any sex differences in the verbal domain (e.g., Hyde \& Linn, 1988). This conclusion is based on tests of reading comprehension, vocabulary, and verbal reasoning. All are complex verbal tasks that, in adult readers, may have little to do with sex differences in phonological processing. However, such sex differences may have a direct bearing on the acquisition of early reading skills, on the methods used in teaching those skills, and, especially, on the early reading problems frequently found in boys.

\section{REFERENCES}

BADDEley, A. D. (1992). Working memory. Science, 225, 556-559.

BARON, J. (1979). Orthographic and word-specific mechanisms in children's reading of words. Child Development, 50, 60-72.

CARroll, J. B. (1993). Human cognitive abilities: A survey of factoranalytic studies. New York: Cambridge University Press.

CHOMSKY, N., \& HALLE, M. (1968). The sound pattern of English. New York: Harper \& Row.

FaiRWEATHER, H. (1976). Sex differences in cognition. Cognition, 4, 231-280.

FEINGOLD, A. (1988). Cognitive gender differences are disappearing. American Psychologist, 43, 95-103.

FRosT, R. (1998). Toward a strong phonological theory of visual word recognition: True issues and false trails. Psychological Bulletin, 123, 71-99.
Garai, J. E., \& Scheinfeld, A. (1968). Sex differences in mental and behavioral traits. Genetic Psychology Monographs, 77, 169-299.

GUILFORD, J. P. (1967). The nature of human intelligence. New York: McGraw-Hill

HALPERIN, D. (1989). The disappearance of cognitive gender differences: What you see depends on where you look. American Psychologist, 44, 1156-1158.

HALPERIN, D. (1992). Sex differences in cognitive ability (2nd ed.). Hillsdale, NJ: Erlbaum.

HYDE, J. S., \& LiNN, M. C. (1988). Gender differences in verbal ability: A meta-analysis. Psychological Bulletin, 104, 53-69.

KERNS, K., \& DECKER, S. N. (1985). Multifactorial assessment of reading disability: Identifying the best predictors. Perceptual \& Motor Skills, 60, 747-753.

Lukatela, G., \& Turvey, M. T. (1993). Similar attentional, frequency, and associative effects for pseudohomophones and words. Journal of Experimental Psychology: Human Perception \& Performance, 19, 166-178.

MACCOBY, E. E., \& JACKLIN, C. N. (1974). The psychology of sex differences. Stanford: Stanford University Press.

Majeres, R. L. (1977). Sex differences in clerical speed: Perceptual encoding vs. verbal encoding. Memory \& Cognition, 5, 468-476.

MAJERES, R. L. (1983). Sex differences in symbol-digit substitution and speeded matching. Intelligence, 7, 313-327.

MaJERES, R. L. (1988). Comparison processes and sex differences in speeded matching. Intelligence, 12, 149-165.

MAJERES, R. L. (1990). Sex differences in comparison and decision processes when matching strings of symbols. Intelligence, 14, 357-370.

MCGuinNess, D. (1981). Auditory and motor aspects of language development in males and females. In A. Ansara, N. Geshwind, A. Galaburda, A. Marilyn, \& N. Gartrell (Eds.), Sex differences in dyslexia (pp. 56-72). Towson, MD: Orton Dyslexia Society.

POSNER, M. I. (1978). Chronometric explorations of mind. Hillsdale, NJ: Erlbaum.

Pugh, K. R., Shaywitz, B. A., Shaywitz, S. E., Shankweiler, D. P., Katz, L., Fletcher, J. M., Skudlarski, P., Fulbright, R. K., Constable, R. T., Bronen, R. A., Lacadie, C., \& Gore, J. C. (1997). Predicting reading performance from neuroimaging profiles: The cerebral basis of phonological effects in printed word identification. Journal of Experimental Psychology: Human Perception \& Performance, 23, 299-318.

RACK, J. P., SNowling, M., \& OLSON, R. K. (1992). The nonword reading deficit in developmental dyslexia: A review. Reading Research Quarterly, 27, 28-53.

Schneidler, G. R., \& Paterson, D. G. (1942). Sex differences in clerical aptitude. Journal of Educational Psychology, 33, 303-309.

Shaywitz, B. A., Shaywitz, S. E., Pugh, K. R., Constable, R. T., Skudlarski, P., Fulbright, R. K., Bronen, R. A., Fletcher, J. M., ShanKWEILER, D. P., KaTZ, L., \& GoRE, J. C. (1995). Sex differences in functional organization of the brain for language. Nature, 373, 607-609.

Stanovich, K. E., \& SiEgel, L. S. (1994). The phenotypic performance profile of reading-disabled children: A regression-based test of the phonological-core variable-difference model. Journal of Educational Psychology, 86, 24-53.

TREIMAN, R. (1984). Individual differences among children in spelling and reading styles. Journal of Experimental Child Psychology, 37, 463-477.

(Manuscript received November 3, 1997; revision accepted for publication March 14, 1998.) 